\title{
Molecularly Imprinted Nanoreactors for Regioselective Huisgen 1,3-Dipolar Cycloaddition Reaction
}

Huiqi Zhang, ${ }^{\dagger}$ Theeraphon Piacham, ${ }^{\dagger}$ Mark Drew, ${ }^{\ddagger}$ Marcel Patek, ${ }^{\ddagger}$ Klaus Mosbach ${ }^{\dagger}$ and Lei Ye ${ }^{\dagger} *$

† Pure and Applied Biochemistry, Chemical Center, Lund University, Box 124, 22100 Lund, Sweden

${ }^{\star}$ Combinatorial Technologies Center, Sanofi-Aventis, 1580 E. Hanley Boulevard, Tucson, AZ 85737 , USA

\section{${ }^{1} \mathrm{H}$ NMR titration experiments}

${ }^{1} \mathrm{H}$ NMR spectra were recorded on a Bruker $400 \mathrm{MHz}$ spectrometer. The triazole (3a) was dissolved in toluene- $\mathrm{d}_{8}$ at a fixed concentration of $45 \mathrm{mM}$. Increasing amount of MAA was added into the triazole solution, followed by measuring the down-field shifts of the proton signals of the triazole.

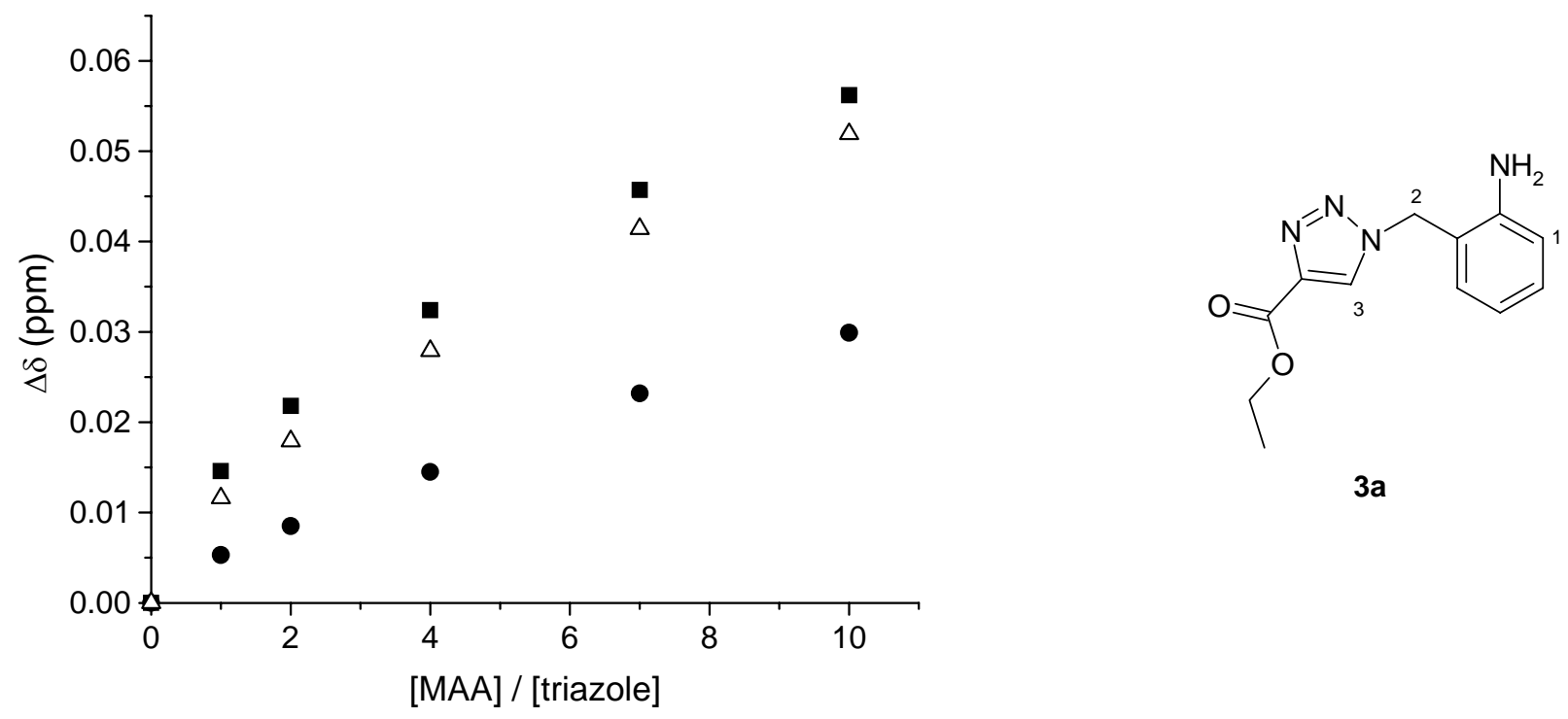

Figure S1. Complexation-induced chemical shift change for 3a at positions $1(\bullet), 2(\Delta)$ and $3(\boldsymbol{\bullet})$.

\section{Preparation of molecularly imprinted polymer MIP(3a) and control polymer CP(За)}

A solution of 3a $(0.5 \mathrm{mmol})$, MAA $(2.0 \mathrm{mmol})$, EDMA $(10.0 \mathrm{mmol})$ and 2,2' -azobisisobutyronitrile $(0.18 \mathrm{mmol})$ in anhydrous toluene $(2 \mathrm{~mL})$ was saturated with argon. The solution was then heated to 65 ${ }^{\circ} \mathrm{C}$ for $24 \mathrm{~h}$. The obtained polymer block was ground into fine particles, which were repeatedly washed with methanol containing $10 \%$ of acetic acid, acetone, and dried in vacuo. The MIP particles were further extracted with toluene in a Soxhlet extractor for 2 days, washed with methanol and dried in 
vacuo. A non-imprinted control polymer was prepared in the same way except that the template was not added.

\section{Equilibrium binding experiment with MIP (3a) and CP (3a)}

Test compounds $(0.1 \mathrm{mg})$ were incubated with polymer particles in anhydrous toluene $(1 \mathrm{~mL})$ at $22{ }^{\circ} \mathrm{C}$ overnight. After centrifugation, the amount of the test compounds remaining in the supernatant was quantified by HPLC analysis.

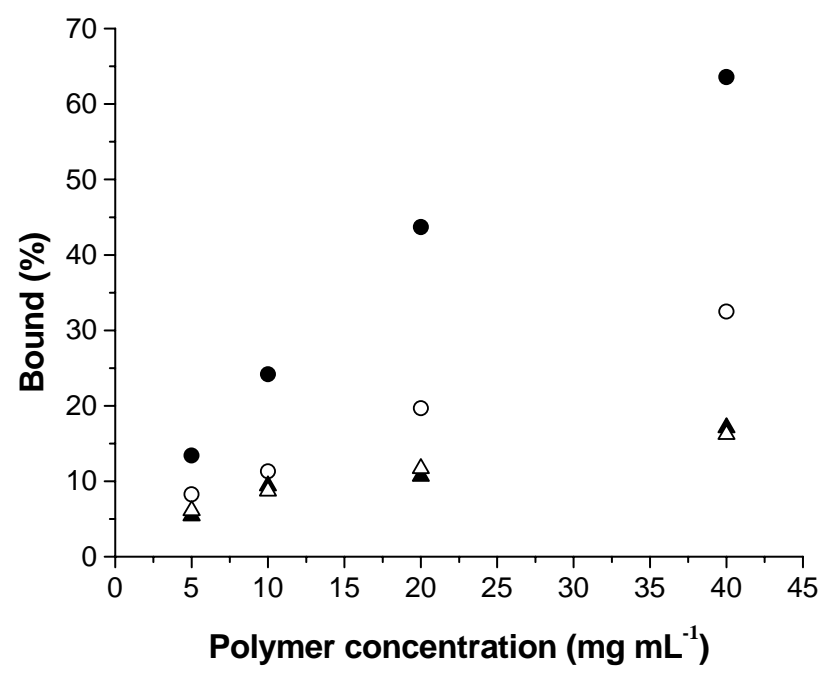

Figure S2. Equilibrium binding of 3a (circle) and 4a (triangle) on different amount of MIP(3a) (solid symbol) and CP(3a) (open symbol).

\section{HPLC-MS analysis}

HPLC-MS analyses were carried out on a SunFire ${ }^{\mathrm{TM}} \mathrm{C}_{18}(3.5 \mu \mathrm{m}, 2.1 \times 50 \mathrm{~mm})$ column mounted on a Waters 2695 Separation Module. Solvent A: 0.1\% formic acid in water, Solvent B: methanol. Flow rate: $0.3 \mathrm{~mL} \mathrm{~min}^{-1}$. Gradient elution: 0-1.5 min, 5-100\% B; 1.5-2 min, 100\% B; 2-2.1 min, 100-5\% B; 2.1-3 $\min , 5 \%$ B (3a, 4a, 3c, 4c); 0-3 min, 50-100\% B; 3-3.5 min, 100\% B; 3.5-3.6 min, 100-50\% B; 3.6-5 $\min , 50 \%$ B $(3 \mathbf{b}, \mathbf{4 b})$. The triazole compounds were detected with a Waters Quattro micro API mass spectrometer in positive mode, using either MRM $(\mathrm{ES}+247.1>105.5$ for 3a and 4a; ES+ 233.0 $>105.6$ for 3c and 4c) or SIR (ES+232.1 for $\mathbf{3 b}$ and $\mathbf{4 b})$ monitoring.

\section{General procedure for MIP-assisted 1,3-dipolar cycloaddition of azides and alkynes}

Polymer particles $(40 \mathrm{mg})$ were stirred in a solution of 2-aminobenzyl azide (2a, $80 \mathrm{nmol})$ in anhydrous toluene $(800 \mu \mathrm{L})$ at $22{ }^{\circ} \mathrm{C}$ for $2.5 \mathrm{~h}$. A solution of ethyl propiolate $(1 \mathrm{a}, 400 \mathrm{nmol})$ in anhydrous toluene $(200 \mu \mathrm{L})$ was added. The mixture was stirred at $22{ }^{\circ} \mathrm{C}$ for $5.5 \mathrm{~h}$, then heated to $75{ }^{\circ} \mathrm{C}$ for $110 \mathrm{~h}$. After being cooled down to ambient temperature, the mixture was centrifuged and the supernatant collected. The polymer particles were washed with anhydrous toluene $(1 \mathrm{~mL})$ and centrifuged again. The supernatant was pooled with that obtained from the previous centrifugation. The combined toluene solution was dried in vacuo. The remaining polymer particles were stirred in $1 \mathrm{~mL}$ of methanol:acetic 
acid $(9: 1, \mathrm{v} / \mathrm{v})$ for $2 \mathrm{~h}$. After centrifugation, the supernatant was collected and dried in vacuo. The amount of product obtained from the toluene phase and that recovered by methanol:acetic acid wash was quantified by LC-MS analysis.

To quantify possible template leakage from MIP(3a), the imprinted polymer particles were stirred in 1 $\mathrm{mL}$ of anhydrous toluene at $22^{\circ} \mathrm{C}$ for $8 \mathrm{~h}$, with and without addition of $80 \mathrm{nmol}$ of $\mathbf{2 a}$. The mixture was heated to $75^{\circ} \mathrm{C}$ for $110 \mathrm{~h}$, and then worked up in the same procedure as used in the MIP-assisted 1,3dipolar cycloaddition reaction.

\section{Kinetic study of 1,3-dipolar cycloaddition of 1a and 2a}

Polymer particles $(10 \mathrm{mg})$ were stirrer in a solution of $\mathbf{2 a}(80 \mathrm{nmol})$ in anhydrous toluene $(800 \mu \mathrm{L})$ at 22 ${ }^{\circ} \mathrm{C}$ for $2.5 \mathrm{~h}$. A solution of $1 \mathrm{a}(400 \mathrm{nmol})$ in anhydrous toluene $(200 \mu \mathrm{L})$ was then added. The mixture was further stirred at $22{ }^{\circ} \mathrm{C}$ for $5.5 \mathrm{~h}$, and then heated to $75{ }^{\circ} \mathrm{C}$. After a certain reaction time, the mixture was cooled to ambient temperature, and worked up using the same post-reaction treatment. The triazole products were quantified using the same HPLC-MS analysis.

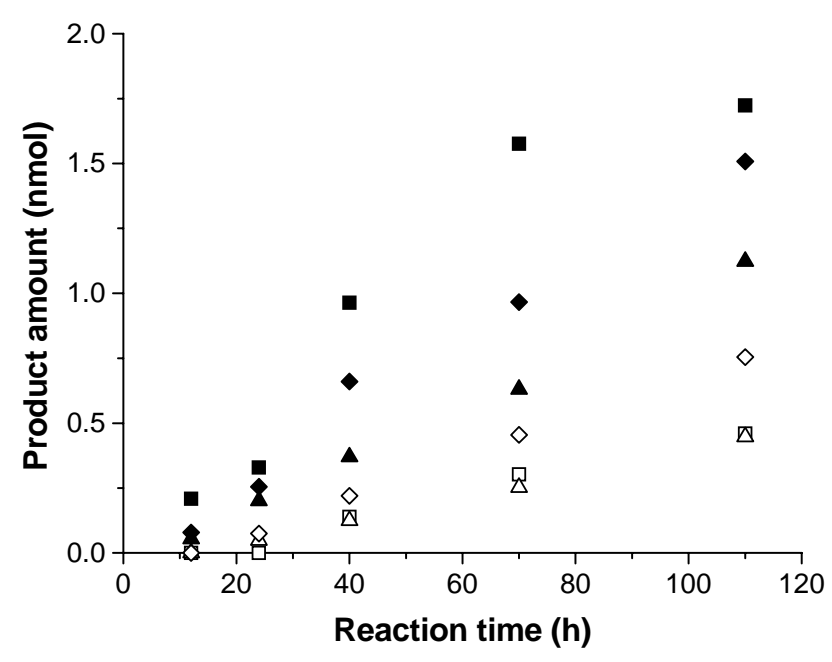

Figure S3. The amount of 3a (solid symbols) and 4a (open symbols) formed at different reaction time, in the presence of MIP(3a) (square), CP(3a) (triangle), and without addition of polymer (diamond). 